\title{
Editorial
}

Nephrology

\section{Does an Acid-Milieu in Chronic Kidney Disease Contribute to Its Increased Cardiovascular Mortality?}

\author{
Donald E. Wesson ${ }^{\mathrm{a}} \mathrm{b}$ \\ Department of Internal Medicine ${ }^{\mathrm{a} B a y l o r}$ Scott and White Health, and ${ }^{\mathrm{b}}$ Texas A\&M College of Medicine, \\ Dallas, Tex., USA
}

Patients with chronic kidney disease (CKD) suffer premature death compared to CKD patients with comparable underlying disease but no CKD [1], and this CKDrelated mortality is further increased in the presence of metabolic acidosis [2, 3]. Observational studies support that the more severe the metabolic acidosis as indicated by lower serum bicarbonate concentration $\left(\left[\mathrm{HCO}_{3}\right]\right)$ the greater the mortality in patients with stages 3 and 4 CKD [4]. Interestingly, the inverse relationship between serum $\left[\mathrm{HCO}_{3}\right]$ and mortality in $\mathrm{CKD}$ includes levels of serum $\left[\mathrm{HCO}_{3}\right]$ which extend into the normal range [5]. The importance of the latter observation is enhanced by studies supporting positive acid balance with acid retention in CKD patients with reduced estimated glomerular filtration rate (eGFR) but with serum $\left[\mathrm{HCO}_{3}\right]$ within the normal range $[6,7]$. These data raise the intriguing hypothesis that treatment of metabolic acidosis in CKD or its associated acid retention in those with reduced glomerular filtration rate (GFR) but without metabolic acidosis reduces CKD-related mortality.

Cardiovascular disease is a major contributor to the increased mortality of CKD [1] and its contribution increases as eGFR decreases [8]. The risk for metabolic acidosis in CKD also increases as GFR decreases $[9,10]$, positing that metabolic acidosis or acid retention contributes to increased CKD-related cardiovascular mortality. Inflammation caused by metabolic acidosis [11] might pro-

\section{KARGER}

E-Mail karger@karger.com

www.karger.com/ajn mote the increased atherosclerosis described in $\mathrm{CKD}$ [12]. Observational studies show that low serum $\left[\mathrm{HCO}_{3}\right]$ is associated with increased incidence of hypertension [13], a major contributor to cardiovascular disease. In addition, high dietary acid increases the risk for CKD patients with reduced GFR to develop metabolic acidosis [14] and increases the risk for subsequent development of hypertension in children [15]. Furthermore, metabolic acidosis also enhances deposition of $\beta_{2}$-microglobulin in many tissues, including the heart [16]. Together, these data support exploration of the potential contribution of metabolic acidosis and/or acid retention to the excess cardiovascular mortality of CKD.

As noted, high dietary acid intake increases the risk for metabolic acidosis in CKD patients with reduced GFR [14]. Diets in developed societies are largely acid-producing due to high intake of acid-producing animal protein combined with comparatively low intake of base-producing proteins from fruits and vegetables [17]. These acidproducing diets increase net endogenous acid production [18] and typically do so without inducing frank metabolic acidosis in individuals with relatively preserved GFR [19] but might do so in those with very low GFR [14]. Nevertheless, these high acid diets might induce acid retention in CKD patients with reduced eGFR even in the setting of normal serum $\left[\mathrm{HCO}_{3}\right][6,7]$. Reducing dietary acid with $\mathrm{Na}^{+}$-based dietary alkali or base-producing
(C) 2016 S. Karger AG, Basel

0250-8095/16/0436-0408\$39.50/0 
food components like fruits and vegetables improves metabolic acidosis [20] and reduces acid retention [6] in CKD patients with reduced eGFR. Consequently, CKD patients in developed societies face a constant dietary acid challenge, putting them at risk for metabolic acidosis and/ or acid retention. The data support examination of the potential efficacy of dietary acid reduction to ameliorate any untoward consequences of this high acid diet, potentially including increased cardiovascular mortality in CKD.

Dobre et al. [21] have taken a much welcomed step toward examining the potential contribution of metabolic acidosis and/or acid retention, using low serum $\left[\mathrm{HCO}_{3}\right]$ as a surrogate, to increased cardiovascular mortality in CKD. The authors used the Chronic Renal Insufficiency Cohort database to assess whether serum $\left[\mathrm{HCO}_{3}\right]$ is independently associated with structural and functional cardiac abnormalities in CKD patients with mean eGFR $42.5 \mathrm{ml} / \mathrm{min} / 1.73 \mathrm{~m}^{2}$. They report that overall prevalence of left ventricular (LV) hypertrophy (LVH) was higher with lower levels of serum $\left[\mathrm{HCO}_{3}\right]$ (51.2\%, with $57.8,50.9$ and $47.7 \%$ for serum $\left[\mathrm{HCO}_{3}\right]$ categories $<22,22-26$ and $>26 \mathrm{mmol} / \mathrm{l}$, respectively). They report that subjects with low serum $\left[\mathrm{HCO}_{3}\right]$ were more likely to have $\mathrm{LVH}$ and abnormal LV geometry but interestingly, the association was not statistically significant after adjustment for demographics, traditional cardiovascular risk factors, medications and kidney function. The authors found no association between serum $\left[\mathrm{HCO}_{3}\right]$ and systolic or diastolic dysfunction, and during follow-up they found no significant changes in LV mass or ejection fraction within any serum $\left[\mathrm{HCO}_{3}\right]$ strata. They concluded that serum $\left[\mathrm{HCO}_{3}\right]$ was associated with $\mathrm{LV}$ mass and concentric LVH but that this association was attenuated after adjustment for clinical factors, suggesting that cardiac effects of these serum $\left[\mathrm{HCO}_{3}\right]$ levels in $\mathrm{CKD}$ are mediated through as yet unknown mechanisms.

The observation that the association of serum $\left[\mathrm{HCO}_{3}\right]$ with the described cardiac abnormalities was no longer significant after adjusting for traditional cardiovascular risk factors is not surprising. Such adjusting factors that might be relevant to serum $\left[\mathrm{HCO}_{3}\right]$ include eGFR, hypertension and smoking. As noted, metabolic acidosis increases in incidence as GFR decreases $[9,10]$; so low serum $\left[\mathrm{HCO}_{3}\right]$ might track with reduced eGFR. Also, metabolic acidosis and increased dietary acid is associated with hypertension, such that low serum $\left[\mathrm{HCO}_{3}\right]$ might also be associated be linked with hypertension. In addition, smoking is associated with kidney injury and faster nephropathy progression $[22,23]$; so smoking might

Low Serum $\left[\mathrm{HCO}_{3}\right]$ and Cardiac

Abnormalities track with reduced GFR and with the latter's stated relationship to low serum $\left[\mathrm{HCO}_{3}\right]$. None of these associations necessarily preclude testing whether treatment of metabolic acidosis and/or acid retention in CKD patients reduces cardiovascular or other contributors to the excess mortality of CKD.

Dobre et al. [21] report makes at least 3 important contributions to the evolving story of the potential untoward effects of an acid milieu in CKD. First, in light of evolving understanding of the effect of an acid milieu in CKD on nephropathy progression [24-26], the authors have importantly directed attention to the potential role of this acid milieu on cardiovascular disease. Second, the report of Dobre et al. [21] comprehensively documents the high prevalence of cardiac abnormalities in this CKD cadre, which is quite representative of the US CKD population not requiring kidney replacement therapy. Third, the data reported by the authors support that low serum $\left[\mathrm{HCO}_{3}\right]$ per se, and by possible extension metabolic acidosis, is not in and of itself a risk factor for these cardiac abnormalities in CKD but instead is linked to more traditional risk factors. The latter observation opens potential research avenues to determine how metabolic acidosis might be linked to traditional cardiovascular risk factors and if treatment of metabolic acidosis ameliorates these factors and their untoward effects on mortality in patients with CKD.

As noted by Dobre et al. [21], metabolic acidosis and acid retention induce increased activity of humoral systems, which in high levels and/or sustained over time might yield untoward effects on heart and vascular function. Systems whose activities are increased by an acid milieu in CKD include angiotensin II [26], aldosterone [6] and endothelin [6]. Dietary acid reduction using mineral-based alkali $[6,26]$ or base-inducing fruits and vegetables [26] reduces activity of at least some of these humoral systems. Future studies will determine if these humoral and possible other beneficial effects dietary acid reduction translate into reductions in cardiovascular and/or overall CKD-related mortality. If this intervention proves effective, further studies will also help determine when in the course of CKD should dietary acid reduction be instituted. Specifically, should dietary acid reduction commence with the onset of metabolic acidosis, when GFR is reduced but serum $\left[\mathrm{HCO}_{3}\right]$ remains within the normal range, or when signs of kidney injury appear, such as albuminuria, even when eGFR and serum $\left[\mathrm{HCO}_{3}\right]$ remain normal?

Current guidelines recommend treatment of CKDrelated metabolic acidosis when serum total $\left[\mathrm{HCO}_{3}\right]$ is 
$<22 \mathrm{mEq} / 1$ [27]. That these guidelines require revisiting is evidenced by studies showing that dietary acid reduction ameliorates nephropathy progression in CKD patients with reduced eGFR and serum $\left[\mathrm{HCO}_{3}\right] 22-24$ $\mathrm{mEq} / \mathrm{l}[26]$ and in those with reduced eGFR but with normal serum $\left[\mathrm{HCO}_{3}\right]$ [25]. The authors of this recommen- dation state that it is based on 'evidence and opinion' [27] but cautioned that 'more research is needed on the longterm effects of correcting acidemia on clinical outcomes...' [27]. The report of Dobre et al. [21] helps determine some directions for this additionally needed research.

\section{References}

1 US Renal Data System: USRDS 2014 Annual Data Report: The National Institutes of Health. Bethesda, National Institute of Diabetes and Digestive and Kidney Diseases, 2015.

2 Kovesdy CP, Anderson JE, Kalantar-Zadeh K: Association of serum bicarbonate levels with mortality in patients with non-dialysis-dependent CKD. Nephrol Dial Transplant 2009; 24:1232-1237.

3 Menon V, Tighiouart H, Vaughn NS, et al: Serum bicarbonate and long-term outcomes in CKD. Am J Kidney Dis 2010;56:907-914.

4 Navaneethan SD, Schold JD, Arrigain S, et al: Serum bicarbonate and mortality in stage 3 and stage 4 chronic kidney disease. Clin J Am Soc Nephrol 2011;6:2395-2402.

5 Raphael K, Wei G, Baird B, et al: Higher serum bicarbonate levels within the normal range are associated with better survival and renal outcomes in African Americans. Kidney Int 2011;79:356-362.

6 Wesson DE, Simoni J, Broglio K, Sheather S: Acid retention accompanies reduced GFR in humans and increases plasma levels of endothelin and aldosterone. Am J Physiol Renal Physiol 2011;300:F830-F837.

7 Vallet M, Metzger M, Haymann JP, et al: Urinary ammonia and long-term outcomes in chronic kidney disease. Kidney Int 2015;88: 137-145.

8 Go AS, Chertow GM, Fan D, McCulloch CE, Hsu CY: Chronic kidney disease and the risks of death, cardiovascular events, and hospitalization. N Engl J Med 2004;351: 1296-1305.

9 Hsu CY, Chertow GM: Elevations of serum phosphorus and potassium in mild to moderate chronic renal insufficiency. Nephrol Dial Transplant 2002;17:1419-1425.
10 Clase CM, Kiberd BA, Garg AX: Relationship between glomerular filtration rate and the prevalence of metabolic abnormalities: results from the Third National Health and Nutrition Examination Survey (NHANES III). Nephron Clin Pract 2007;105:c178-c184.

11 Rao M, Wong C, Kanetsky P, et al: Cytokine gene polymorphism and progression of renal and cardiovascular diseases. Kidney Int 2007; 72:549-556.

12 Recio-Mayoral A, Banerjee D, Streather C, et al: Endothelial dysfunction, inflammation and atherosclerosis in chronic kidney disease - a cross-sectional study of predialysis, dialysis and kidney-transplantation patients. Atherosclerosis 2011;216:446-451.

13 Mandel EI, Forman JP, Curhan GC, Taylor EN: Plasma bicarbonate and odds of incident hypertension. Am J Hypertens 2013;26:14051412.

14 Adeva MM, Souto G: Diet-induced metabolic acidosis. Clin Nutr 2011;30:416-421.

15 Krupp D, Shi L, Remer T: Longitudinal relationships between diet-dependent renal acid load and blood pressure development in healthy children. Kidney Int 2014;85:204210.

16 Sonikian M, Gogusev J, Zingraff J, et al: Potential effect of metabolic acidosis on beta 2-microglobulin generation: in vivo and in vitro studies. J Am Soc Nephrol 1996;7:350-356.

17 Remer T: Influence of nutrition on acid-base balance - metabolic aspects. Eur J Nutr 2001; 40:214-220.

18 Frassetto LA, Todd KM, Morris RC Jr, Sebastian A: Estimation of net endogenous noncarbonic acid production in humans from diet potassium and protein contents. Am J Clin Nutr 1998;68:576-583.
19 Kurtz I, Maher T, Hulter HN, et al: Effect of diet on plasma acid-base composition in normal humans. Kidney Int 1983;24:670-680.

20 Goraya N, Simoni J, Jo CH, Wesson DE: A comparison of treating metabolic acidosis in CKD stage 4 hypertensive kidney disease with fruits and vegetables or sodium bicarbonate. Clin J Am Soc Nephrol 2013;8:371-381.

21 Dobre M, Roy J, Tao K, et al: Serum bicarbonate and structural and functional cardiac abnormalities in CKD - a report from the CRIC study. Am J Nephrol 2016;43:411-420.

22 Orth SR: Smoking - a renal risk factor. Nephron 2000;86:12-26.

23 Phisitkul K, Hegazy K, Chuahirun T, et al: Continued smoking exacerbates but cessation ameliorates progression of early type 2 diabetic nephropathy. Am J Med Sci 2008;335: 284-291.

24 de Brito-Ashurst I, Varagunam M, Raftery MJ, et al: Bicarbonate supplementation slows progression of CKD and improves nutritional status. J Am Soc Nephrol 2009;20:2075-2084.

25 Mahajan A, Simoni J, Sheather S, et al: Daily oral sodium bicarbonate preserves glomerular filtration rate by slowing its decline in early hypertensive nephropathy. Kidney Int 2010;78:303-309.

26 Goraya N, Simoni J, Jo CH, Wesson DE: Treatment of metabolic acidosis in patients with stage 3 chronic kidney disease with fruits and vegetables or oral bicarbonate reduces urine angiotensinogen and preserves glomerular filtration rate. Kidney Int 2014;86:10311038.

27 KDIGO: KDIGO 2012 clinical practice guideline for the evaluation and management of chronic kidney disease. Kidney Int Suppl 2013;3:73-90. 